\title{
RETRATOS DE SORRISOS: PÚBLICO E PRIVADO ENTRE POLICIAIS MILITARES ${ }^{1}$
}

Fernanda Valli Nummer ${ }^{2}$

O “devir-imagético encaminha uma nova percepção da alteridade” (Gonçalves; Head, 2009, p. 30), basicamente uma expressividade criativa na arte do trabalho com imagens na antropologia. As imagens que compõem este ensaio etnofotográfico foram produzidas por uma interlocutora de pesquisa para a minha apresentação de defesa de tese de doutorado em Antropologia Social na Universidade Federal do Rio Grande do Sul no ano de 2010. À época, comentei com ela que todas as fotos que tinha de meus interlocutores fardados e sorrindo, tanto da pesquisa do mestrado (Nummer, 2005), quanto do doutorado (Nummer, 2016), não foram autorizadas, por eles, a serem divulgadas. Ela prontamente se propôs a fazer as imagens e disse "vai ser difícil, mas eu faço eles rirem". As imagens foram primeiramente autorizadas apenas para a apresentação da tese em slides e apenas, este ano em 2016, para publicação. Cabe destacar que é importante para o objetivo deste ensaio, são as mudanças institucionais que a polícia militar vem passando nas últimas décadas com políticas de proximidade com a população, aumento da escolaridade exigida nos concursos de ingresso, críticas aos excessos cometidos dentro da corporação em nome dos ideais disciplina e hierarquia da militarização.

$\mathrm{Na}$ profissão policial militar a farda é uma das referências simbólicas produtoras de identidade, pois ela consagra o processo de socialização profissional e faz ver a condição social do sujeito (Nummer, 2005). Bourdieu (2014, p. 86) analisando a oposição público e privado e destaca que a separação "público/privado, oficial/oficioso, público/oculto impõem-se ao máximo aos homens públicos". Para além desta análise o autor ainda reforça que há um laço entre o público, o visível e a moralidade e que nas estruturas mentais, da maioria das sociedades, há uma oposição entre o privado, o do desleixo, o do descontrole e o público, o da compostura, o do cuidado e do controle.

Acreditamos que um sorriso ${ }^{3}$ de um indivíduo público pode romper com os limites morais de posturas e gestos prescritos para o uso desta vestimenta, pois manifesta características privadas

\footnotetext{
${ }^{1}$ Meus sinceros agradecimentos a Soldado Liane Cardoso, do Comando Regional de Policiamento Ostensivo do Vale do Taquari, Lajeado, Rio Grande do Sul, pela produção das imagens e pela interlocução em muitos anos de pesquisa.

${ }^{2}$ Socióloga, Dra em Antropologia Social, Professora IFCH-UFPA, Campus Belém. E-mail: nummer@ufpa.br.

${ }^{3}$ Sobre as teorias do riso, ver Minois (2000).
} 
da pessoa que não devem ser explicitadas no exercício da função. Especialmente, o que se se refere aos padrões de compostura ensinados nos cursos de formação, que variam culturalmente entre as instituições e de acordo com os as situações vivenciadas pelos policiais nos diversos tipos de trabalho executados, atividades administrativas ou operacionais de policiamento.

Assim, a relação entre o fardamento e o sorriso, parece estar muito mais associados ao que Goffman (2009) chamou de regulação e controle da conduta na interação no sentido de que a imagem para os outros, aquelas que sairiam nos "meus relatórios" sejam da personalidade pública, indicada por Bourdieu (2014).

A relação que este grupo tem com a imagem que é produzida por pessoas de fora da corporação, especialmente pelos meios de comunicação de massa, é muitas vezes de desconfiança. Geralmente são retratados fardado em situações de violência e suas condutas nestas imagens são avaliadas pela corporação e pelo público em geral, resultando em punições disciplinares ou desvalorização profissional. As consequências sociais da exposição pública, tanto de erros quanto de atos considerados heroicos são carregadas nas trajetórias de vida.

O relato da produção deste ensaio etnofotográfico é mais um exemplo da importância da densidade do trabalho etnográfico e da autêntica interlocução com os pesquisados para a compreensão de que o devir-imagético é uma relação, em que outras formas de apresentação e representação do outro são possíveis.

\section{REFERÊNCIAS}

BOURDIEU, Pierre. Sobre o estado: Cursos no Collège de France (1989-92). São Paulo; Companhia das Letras, 2014.

GOFFMAN, Erving. A representação do eu na vida cotidiana. Petrópolis: Vozes. 2009. GONÇALVES, Marco Antonio; HEAD, Scott (org.). Devires Imagéticos: a etnografia, o outro e suas imagens. Rio de Janeiro: 7Letras, 2009.

MINOIS, Georges. História do riso e do escárnio. São Paulo: Unesp, 2000.

NUMMER, Fernanda Valli. Ser polícia, ser militar: o curso de formação na socialização do policial militar. Niterói: EDUFF, 2005.

NUMMER, Fernanda Valli. Estilos de vida entre soldados da polícia militar: "ser brigadiano" ou "trabalhar na brigada". Alemanha: Novas Edições Acadêmicas, 2016. 

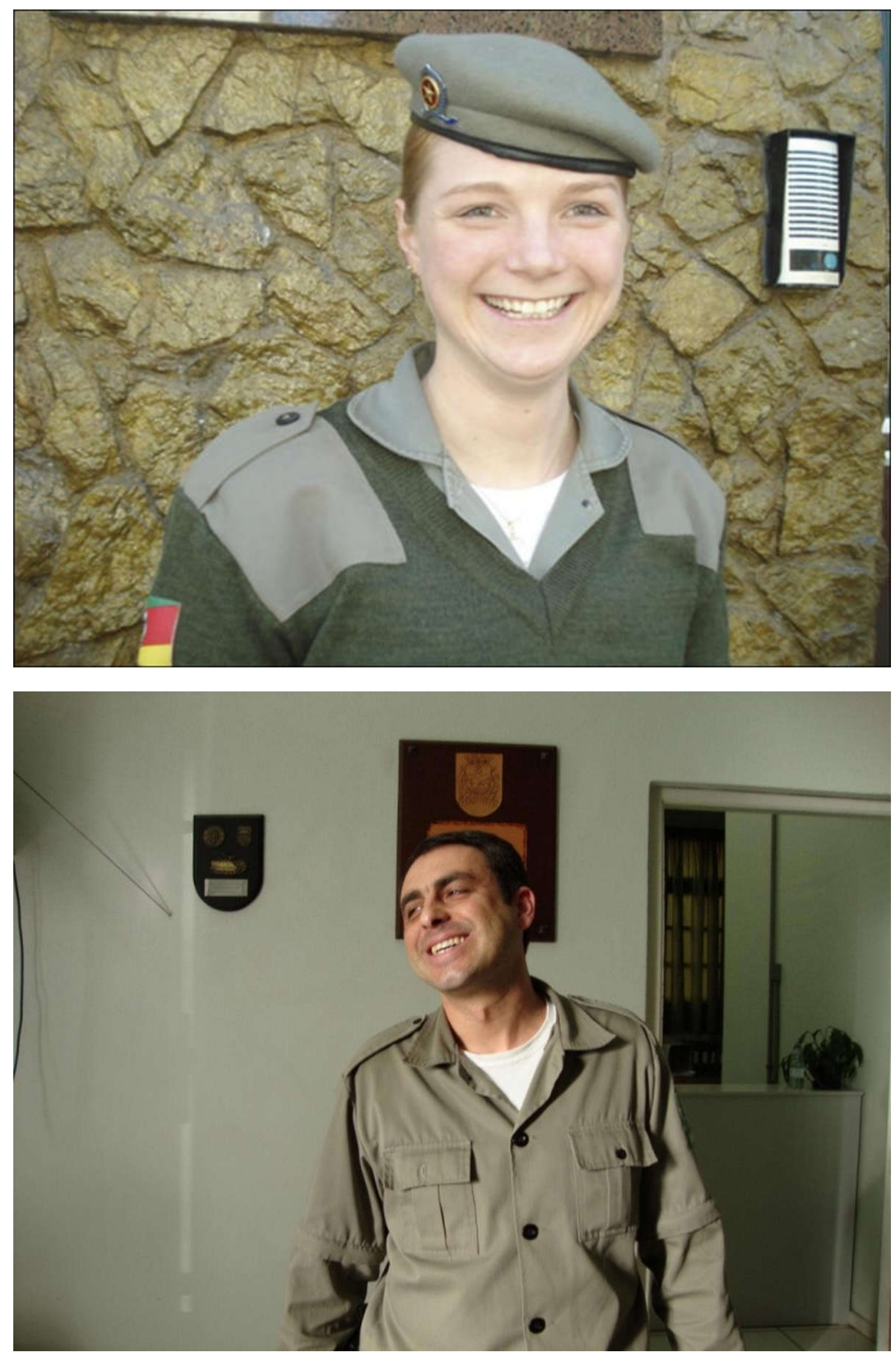

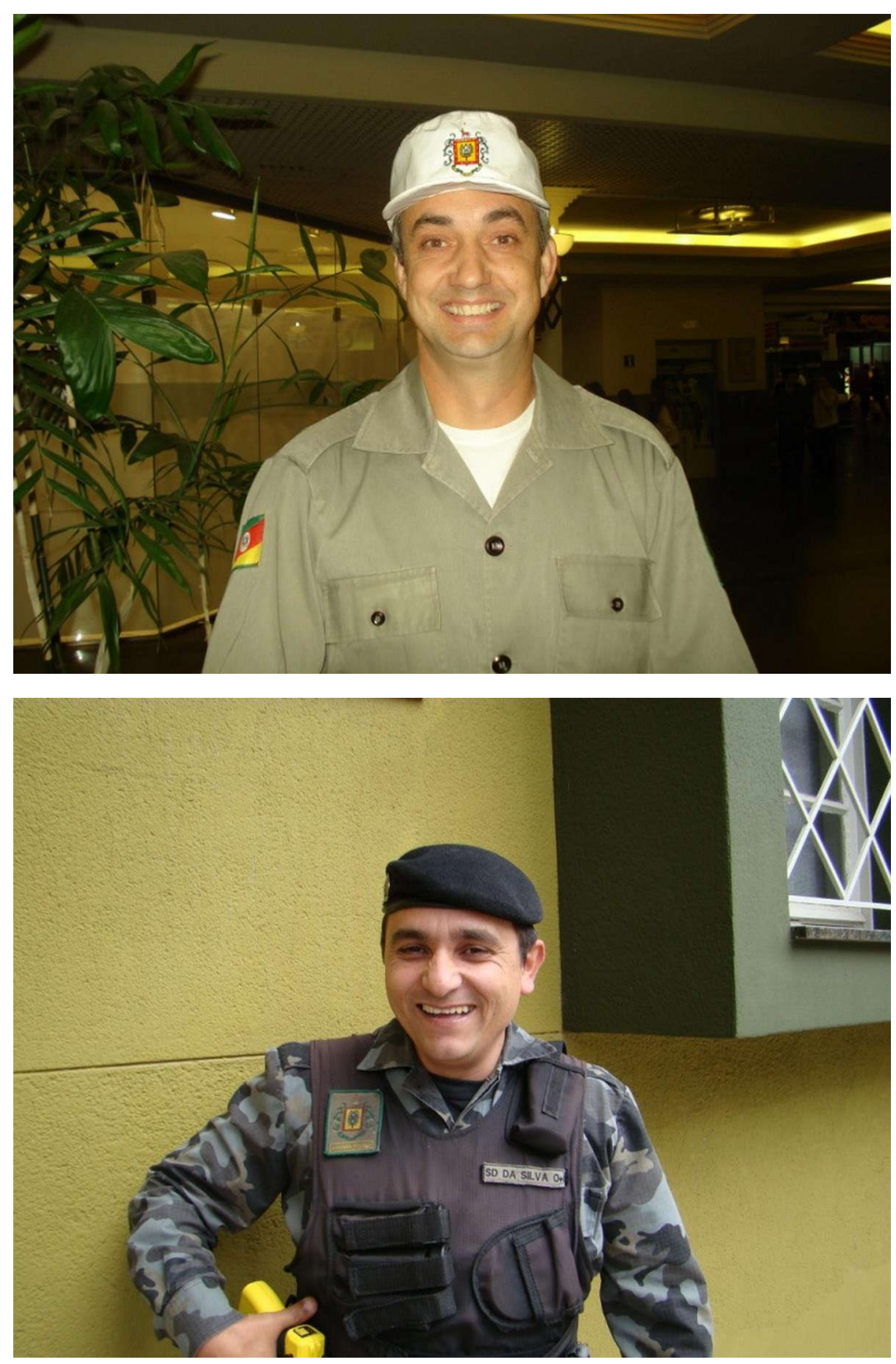

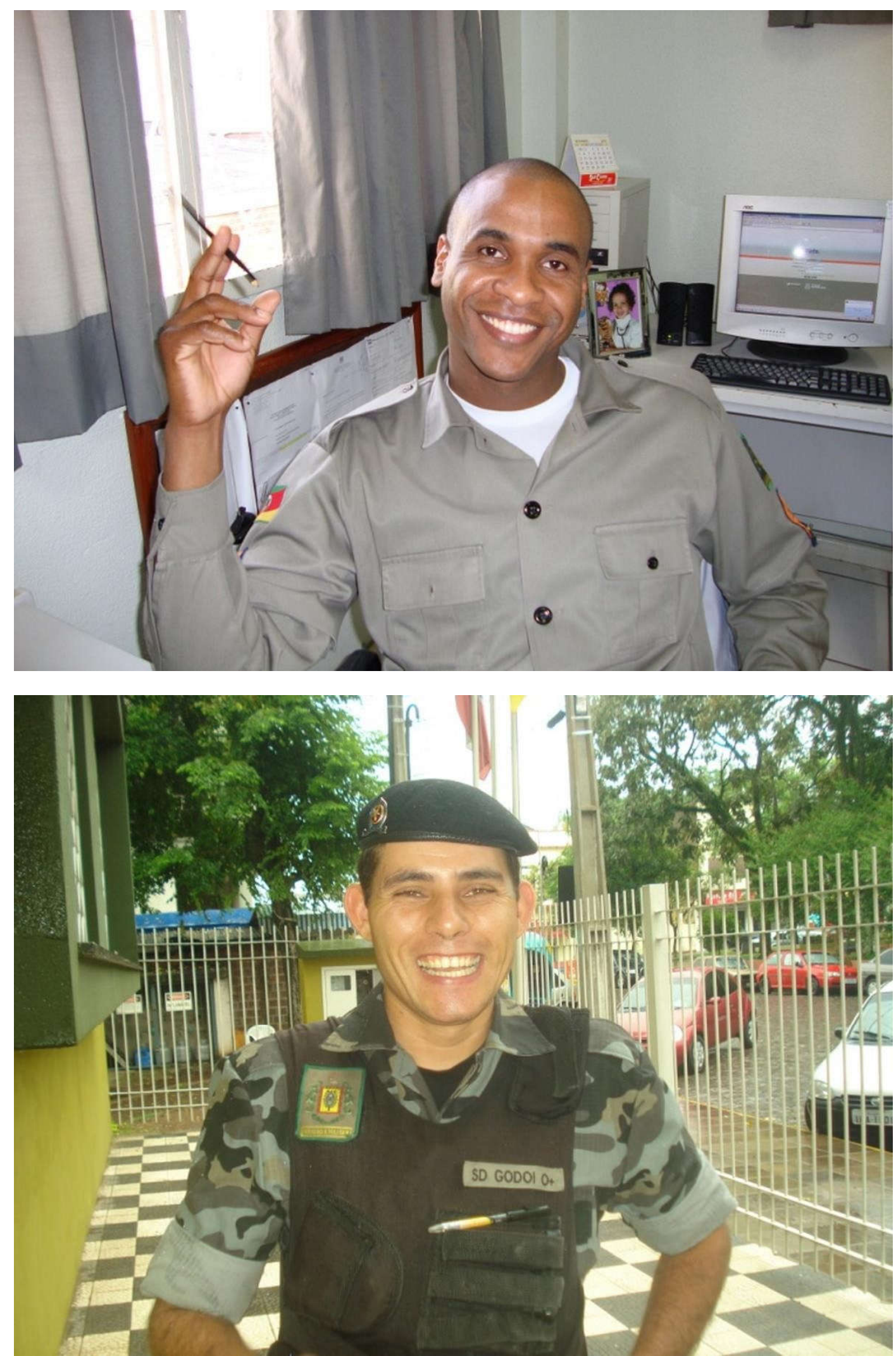

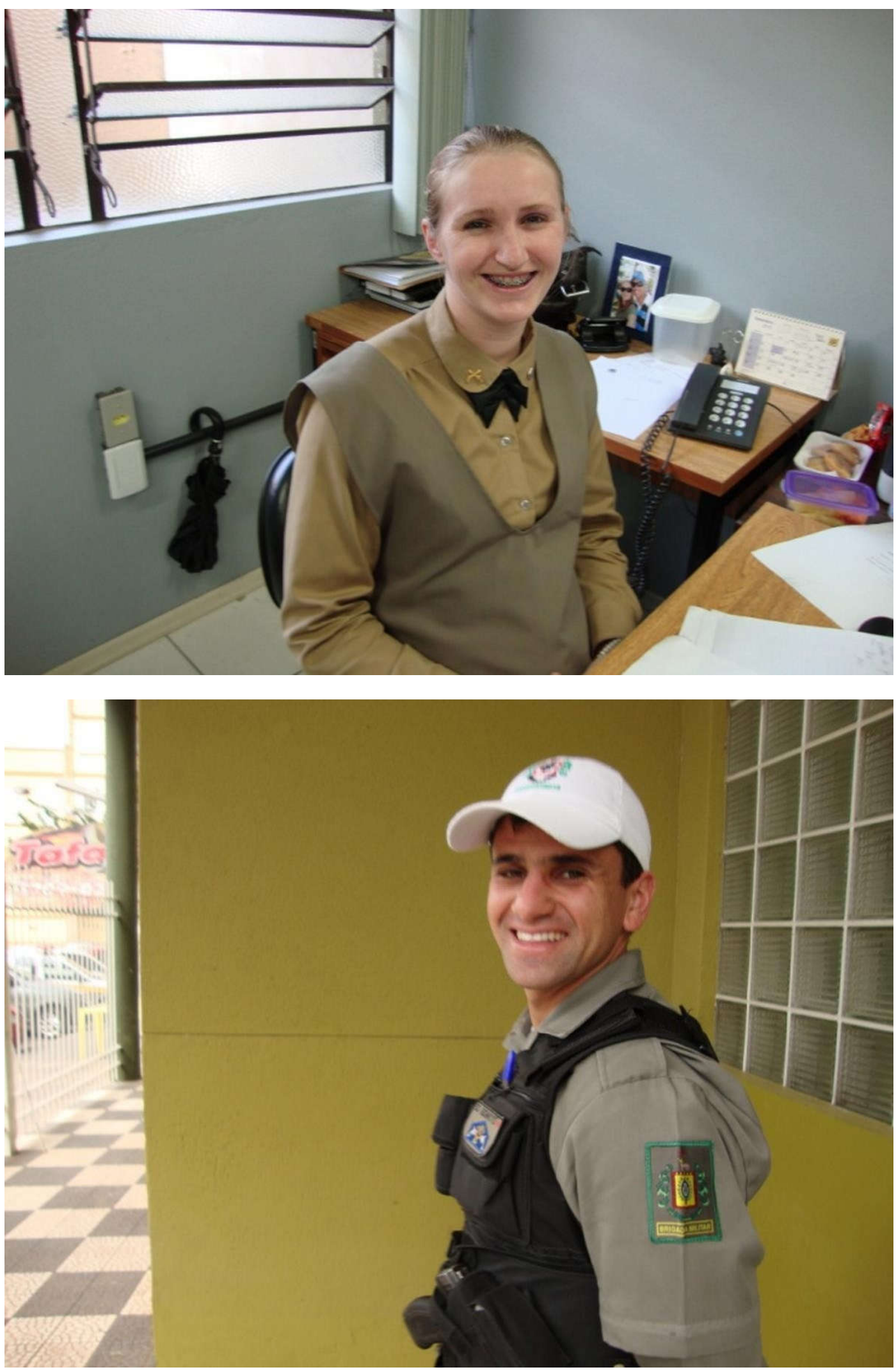


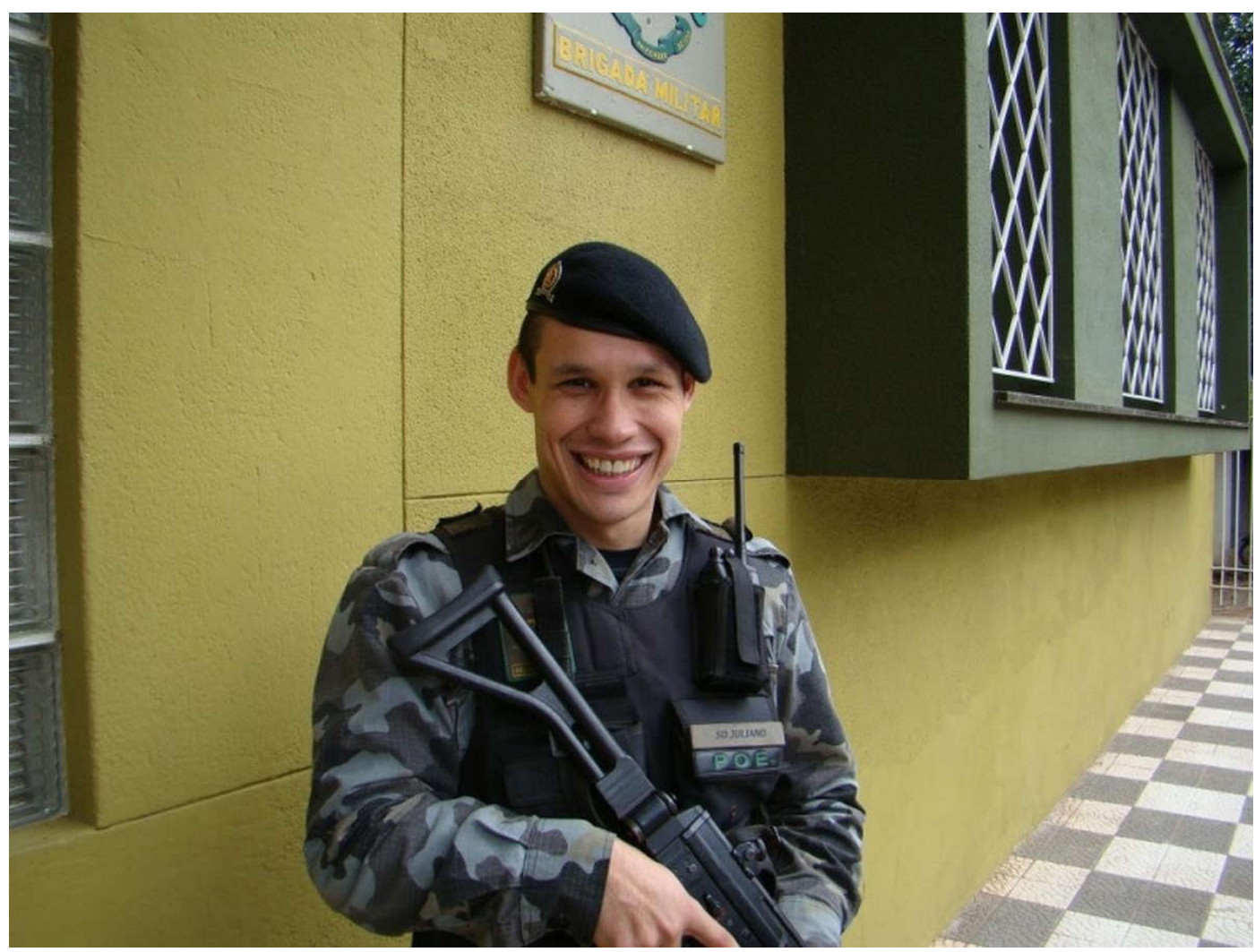

